\title{
Interactive comment on "From fibrous plant residues to mineral-associated organic carbon - the fate of organic matter in Arctic permafrost soils” by Isabel Prater et al.
}

\section{Marijn Van de Broek}

marijn.vandebroek@usys.ethz.ch

Received and published: 3 April 2020

${ }^{*} \mathrm{~A}$ note upfront from the submitting person: This review was prepared by four master students in geography at the University of Zurich. The review was part of an exercise during a second semester master level seminar on "the biogeochemistry of plant-soil systems in a changing world", which is organized by prof. Dr. Michael Schmidt and myself. We would like to highlight that the depth of scientific knowledge and technical understanding of these reviewers represents that of master students. We enjoyed discussing the manuscript in the seminar, and hope that the comments will be helpful for the authors. * 
The manuscript by Prater et al. provides new data on the different physical fractions of soil organic matter from the Lena River Delta in the Arctic. The area on Samoylov Island is characterized by permafrost. The authors investigated soils with respect to the composition and distribution of organic $\mathrm{C}$ among differently stabilized SOM fractions, in order to gain knowledge on the mechanisms stabilizing organic $C$ in Arctic soils, besides impaired decomposition due to low temperatures. The methods consists of the use of sophisticated approaches, separating SOM into different fractions, allowing for a detailed understanding of the stabilization mechanisms of organic carbon in soils. The study is relevant, as there are still rather few analytical approaches to the stabilization mechanisms to assess the variability of $C$ stocks in tundra soils. The research question is particularly relevant as the study deals with a region where permafrost occurs and where soils are both an important store of carbon and other greenhouse gases and are affected by global warming. The authors did not formulate a clear hypothesis or the expected results. Consequently, they did not make a comparison between their results and their original expectations, which makes it difficult to compare the results of the research with other studies.

\section{General comments and suggestions:}

- The research question addressed by the authors is important due to the lack of knowledge on the topic. Indeed, researchers only recently started to understand the importance of cold soils for the global carbon cycle, and thus global climate. As a consequence, only a few studies related to this topic have been made so far. - The authors did not explicitly state any hypotheses. They described their intent of investigating the effect of climate change on the carbon stabilization in permafrost-affected soils, but they remained vague and did not state any kind of expected results. Therefore, it is difficult to understand to what extent the research contributed to their question. - The study site is situated in the river delta of the River Lena. Chemical composition and structure of the soil could be the result of flooding which is not the case for typical arctic permafrost soils. In general, the isle may be more affected by the Lena itself

Printer-friendly version

Discussion paper
Interactive comment

\section{2}


than by the rising temperature. In addition, the closeness of the Siberian sea will have an influence of the isle too, as the ocean moderates the temperatures. Therefore, the study site on the isle Samoylov maybe not representative for arctic permafrost soils in general. - Do you think is the $\mathrm{d} 15 \mathrm{~N}$ a suitable method? There are many uncertainties related to it, which could be elaborated upon.

Specific comments and suggestions:

L. 75-78: Here the authors write about their approach and the aims, which are basically to gain better knowledge on the topic. Since this section is at the end of the introduction, we think that this part is the most suited for adding the research questions and hypotheses. We think this is important, especially because the authors took four soil cores in a vast area that might be highly heterogeneous. Therefore, having expectations related to the SOM fractions you expect to find in this area, including also the stratification of the soil layers could help determining how representative the four soil cores are with respect to the whole study area.

L. 94-97: In this part the methods are described. However, the authors then state that "a detailed description of the study area and the sampling of the soil cores can be found in Zubrzycki et al. (2013)". We advise that the authors include all relevant information also in the presented manuscript. Otherwise, the readers have to go into the literature to find this relevant information.

L. 101-105: Here, the authors describe how samples were collected, but omitted to state how many samples were collected for each SOM fraction and from which soil core they were collected. We advise to provide the number of samples of each SOM fractionation type, because otherwise it might be difficult to interpret the graphs. We also checked the literature but found any information about the number of samples in Zubrzycki et al., 2013.

Fig. 4: The three graphics (figure 4. a, b, c) could be made more similar. Further, for what concerns figure $a$ and $b$, the authors represented only the two extreme values

Printer-friendly version

Discussion paper 
on the x-axis (10 and 100), which makes it difficult to infer the values of the dots in the middle of the graph. Please include more labels on the $x$-axis to make it more continuous and improve readability. We would also advice to put the $x$-axis on the bottom for both graphs ( $a$ and $b$ ) and not once on the top and once on the bottom. Further, we noticed a clear positive correlation between the $\mathrm{C} / \mathrm{N}$ ratio and the $\mathrm{d} 13 \mathrm{C}$, however, since the $\mathrm{C} / \mathrm{N}$ ratio usually decreases during ongoing decomposition, we were expecting the opposite trend. We therefore advise to further explain the meaning of this positive correlation.

Fig.7 \& 8: Graphs 7 and 8 are difficult to interpret and would require more information in the captions to make the graphs understandable without the reader having to look up more information in the main text.

Title: Why was the word "fibrous" included in the title? Almost all plants residues are fibrous, except for plant exudates. Do you specifically looked at fibrous plant residues omitting exudates? Further, the fate of organic matter sounds somewhat dramatic. We think the title could be shortened to, for example: "From plant residues to mineralassociated organic carbon in Arctic permafrost soils".

Interactive comment on Biogeosciences Discuss., https://doi.org/10.5194/bg-2020-52, 2020.

Printer-friendly version

Discussion paper 